\title{
Theoretical Analysis of a New Design of a Concentration Based Solar Distiller
}

\author{
Mokhtar Mohammed ${ }^{1, *}$ and Taha Janan Mourad ${ }^{1}$ \\ ${ }^{1}$ Applied Mechanics and Technologies Research Laboratory, Higher school of technical education teachers-Rabat, \\ Mohammed V University, Royal Army Avenue, Madinat Al Irfane, BP 6207, Rabat, Morocco
}

\begin{abstract}
This paper includes a theoretical study of energy balance for all parts of new design of solar concentration distiller using a parabolic concentrator with a half-cylinder basin. Our goal is to analyze the thermal efficiency of the new device to use in the Morocco's Rabat-Sale-Kenitra region. The methodology concentrates on solving the thermal collector's energy balance equations whose components are the glass cover, the brackish water and half-cylinder absorber. Numerical resolution of the energy balance equations was performed using a MATLAB code based on the method of 4th order Runge-Kutta. The results show a good theoretical performance of the new device.
\end{abstract}

\section{Nomenclature}

$\begin{array}{ll}\mathrm{Q} & \text { Heat transfer flux, W/m }{ }^{2} \\ \mathrm{~h} & \text { Heat transfer coefficient, } \mathrm{W} / \mathrm{m}^{2} . \mathrm{k} \\ \mathrm{Cp} & \text { Specific heat, } \mathrm{J} / \mathrm{kg} . \mathrm{k} \\ \mathrm{I}(\mathrm{t}) & \text { Incident solar radiation, } \mathrm{W} / \mathrm{m}^{2} \\ \mathrm{~L} & \text { Length, } \mathrm{m} \\ \mathrm{M} & \text { Mass, } \mathrm{kg} \\ \mathrm{A} & \text { Area, } \mathrm{m}^{2} \\ \mathrm{t} & \text { Temps, hour } \\ \mathrm{T} & \text { Temperature, }{ }^{\circ} \mathrm{C} \\ \mathrm{dT} & \text { Incremental rise, }{ }^{\circ} \mathrm{C}\end{array}$

Greek letters

$\begin{array}{ll}\varepsilon & \text { Emissivity } \\ \alpha & \text { Absorptivity } \\ \tau & \text { Transmissivity } \\ \mathrm{R} & \text { Reflectivity } \\ \mathrm{K} & \text { Thermal conductivity, W/m.k } \\ \beta & \text { Thermal expansion coefficient, } 1 / \mathrm{k} \\ \text { Subscripts } & \\ \mathrm{a} & \text { Ambient } \\ \mathrm{g} & \text { Glass cover } \\ \mathrm{W} & \text { Saline water } \\ \mathrm{b} & \text { Half-cylinder absorber } \\ \mathrm{c} & \text { Convection } \\ \mathrm{e} & \text { Evaporation } \\ \mathrm{r} & \text { Radiation } \\ \text { ev } & \text { Evaporative } \\ \mathrm{p} & \text { parabolic } \\ \text { aper } & \text { Aperture } \\ \mathrm{PVGIS} & \text { Photovoltaic Geographical } \\ & \text { Information System }\end{array}$

\section{Introduction}

In the world, water forms about $97 \%$ in the oceans, it is also stored as ice in polar places for about $2 \%$, and just of $1 \%$ is fresh water that is required for animals and plants and the needs of human life $[1,2]$.

The world's need for potable water continues to rise day by day because of the increasing growth in the population, industry and agriculture. Nowadays, the scarcity problem threatens even regions that are considered as water-rich. The several issues associated in the world with the lack of fresh and clean water are well documented: 1.2 billion people complain about of lack of access to clean drinking water and more than millions die each year from diseases caused by human excreta or contaminated water [3].

Face to the fresh water shortage, the solar distillation use can be found a promising alternative for turning salty or brackish water into fresh water, by using solar energy which is widely and sufficiently available on Earth [2].

Chouchi et al. [4] showed that the solar energy thermal conversion using solar concentrators allowed salt water to be boiled at high temperatures at pressures equal or higher than atmospheric pressures.

Khalifa et al. [5] performed an experimental analysis on new designs of solar stills of the basin type and designed multiple single and double solar stills. They conducted the tests to determine the impact on results of such changes, such as productivity and efficiency. Some improvements including preheating of feeding water via a solar heater and the use internal and external condensers for condensing vapors along with preheating water for feeding. The results revealed advancements in solar stills production and performance.

El Gharbi et al. [6] conducted a comparative analysis between linear Fresnel reflector and collector's parabolic trough. They found that the linear Fresnel reflector's thermal efficiency and optical quality is lower due to a

* Corresponding author: mokhtaralsharay14@gmail.com 
higher cosine factor and incidence angle effect, but it also has lower costs.

Auti [7] manufactured a solar thermal system consisting of a manual tracking parabolic concentrator, a black receiver and the water vapor passes to the main receiver which is a finned system used for condensation and distilled water collects into a container.

Arunkumar et al. [8] compered a compound parabolic concentrator-tubular solar still(CPC-TSS), a compound conical concentrator (CCC) and a singleslope solar still. The daily yield rate is measured per square meter of CPC-TSS, CCC solar still and single slope solar still absorber area are 6,100,18,000 and 2,100 , respectively. The CCC solar still has been found to produce the maximum yield.

Bouzaid et al. [9] analyzed both experimentally and theoretically the thermal performances and productivity of the stepped solar still new pattern. The results show that there is a good agreement between the experimental measures and the calculation which confirms the mathematical model. The new cascade solar still daily production can achieve important values that can exceed up to $7 \mathrm{~kg} / \mathrm{m} 2$ when compared with other solar still results.

Al-harahsheh et al. [10] performed the water desalination experimental study using a solar still has phase change material (PCM) and linked to a solar collector. They also studied the impact on the fresh water amount generated by the cooling water flow rate, hot water circulation flow rate and basin water level. The results show that the desalinated water output rate was proportional to the increase in ambient temperature and the flow rate of hot water circulation. During the nighttime period the selected PCM operated well to provide energy without any change in thermal behavior. In addition, it was noticed that rising the water level in the basin leads to decrease the productivity.

Lachhab et al. [11] manufactured a solar cogeneration system that consists of a concentrated solar system (CSP) and photovoltaic (PV). They conducted the theoretical and experimental study of heat transfer on system in the (Rabat-sale-kenitra) region. They have developed a calculation code. The findings of the comparison between the experimental data and the numerical solution relating to the different thermal collect temperature are recommended.

The parabolic tough concentrators are the most generally utilized linear concentrator for solar thermodynamic conversion, practically in domestic and industrial areas where operating temperatures between $80{ }^{\circ} \mathrm{C}$ and $160{ }^{\circ} \mathrm{C}$ are needed. The parabolic concentrator is the most encourage technologies to replace nonrenewable energies (nuclear energy and fossil fuels), practically in the industrial sector, like hybrid systems power plants, desalination, air condition, irrigation, or refrigeration [12-15].

\section{New design of solar concentration description}

In the present study, a new design for a solar parabolic concentrator used for water desalination is considered. It consists of two parts that are described below.

\subsection{The parabolic concentrator assembly}

The parabolic trough concentrator has a half-cylinder basin absorber of solar distiller made of copper with an effective selective layer installed in the parabola's focal line. The limited surface that has a high solar radiation absorption coefficient.

The reflector is designed to operate the focal line (f) is $1 \mathrm{~m}$ away the vertex $(\mathrm{V})$, the device aperture $(\mathrm{W})$ is $2.25 \mathrm{~m}$. The equation of the designed system will be:

$$
x^{2}=4 y
$$

The designed dimension, aperture distance is $3 \mathrm{~m}$ and the maximum height at the end of the parabola is $0.47 \mathrm{~m}$.

The angle of rim $\varphi$ defined in terms of the ratio of the width of aperture to the focal length and is such as

$$
\tan \phi=\frac{W / f}{\left[2-\left(\frac{1}{8} \times\left(\frac{W}{f}\right)^{2}\right]\right.}
$$

Where $\mathrm{f}$ and $\mathrm{W}$ the focal length and the aperture width of the system, respectively. The rim angle of the system is $58.72^{\circ}$.

The reflector assembly consists of two parts. A parabolic base made of several pieces of steel flat bar must be supported by steel hollow bar (tube). The other part, the reflector consists of several segments or pieces of mirrors.

\subsection{The half-cylinder basin solar distiller}

The part of the half-cylinder of diameter $0.3 \mathrm{~m}$, designed separately and connected to the basin, constitutes of the solar distiller's bottom part of thickness $0.004 \mathrm{~m}$.

The entire volume of half-cylinder absorber servers as storage of water.

The top solar distiller surface is a glass cover of $(0.36$ $\mathrm{m} \times 3 \mathrm{~m}$ ) area, $0.3 \mathrm{~m}$ height and $0.002 \mathrm{~m}$ thickness.

The top cover places a uniform resting double slope of $30^{\circ}$ on the grooves. The segments of fresh-water collection have a length of $3 \mathrm{~m}$ and a width of $0.030 \mathrm{~m}$.

The center line of half-cylinder basin mounts at the parabolic concentrator's focal line.

The system concentration ratio is the ratio of the aperture area of the parabolic trough concentrator to the half-cylinder receiver area. The system concentration ratio is 4.774 .

A diagram view of the new design of solar concentration is shown in Figure 1. 


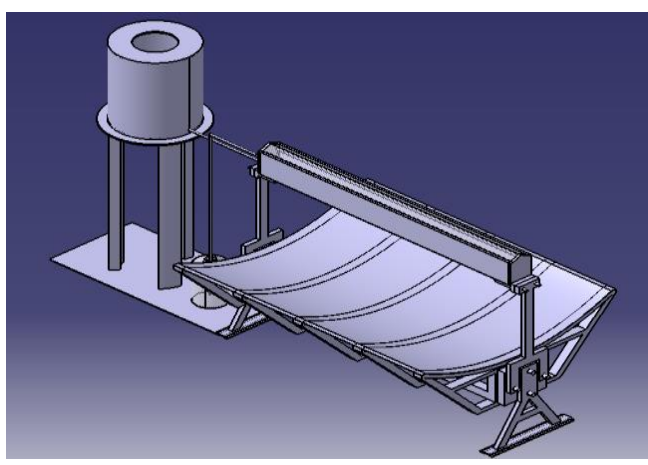

Fig. 1. A diagram view of new design of device

\section{Operation principles of New design of solar concentration}

Solar radiation will fall into the device in two places:

- In half-cylinder basin (absorber surface) which contains brackish water inside the basin through a glass cover.

- In the parabolic concentrator where the radiation will be reflected at the focal line where the absorber surface and solar radiation concentration in the absorbent surface leads to heat the brackish water and rises the temperature.

The brackish water evaporates once heated and the water vapor rises until it touches the inner glass cover surface. Afterwards, the water vapor condenses on the glass cover from the internal surface and becomes fresh water stored and turns into fresh water collected in the segments located on each side of the system.

\section{Mathematical Modeling of Heat Transfer}

The modeling principle is based on an energy balance for the essential elements of the device will be applied to three places: brackish water, glass cover and halfcylinder basin.

Figure 2 shows transversal view of the parabolic concentrator with solar distiller with the heat transfer paths throughout the distiller containing three components (glass cover, brackish water, half -cylinder basin).

The equations of the energy balance are used for determining the temperatures of the elements of the device.

In these equations $T_{g}, T_{w}$ and $T_{b}$ denote the glass temperature, the brackish water temperature and the halfcylinder basin temperature, respectively.

The equations of the energy balance are written based on the following assumptions:

1- The parabola form is symmetrical.

2- The absorber shadow effect on the parabola is negligible.

3- The physical properties are constant for different materials.

4- The heat capacity of the sides and bottom walls is neglected.
5- Constant temperature gradient with water depth and glass cover thickness.

6- Dry air and water vapor are known to be ideal gases.

7- No vapor leakage occurs inside the device.

8- Condensation occurs only the internal glasscover surface.

9- Water level is constant in the half-cylinder basin.

10- Losses from the segments and walls sides are neglected.

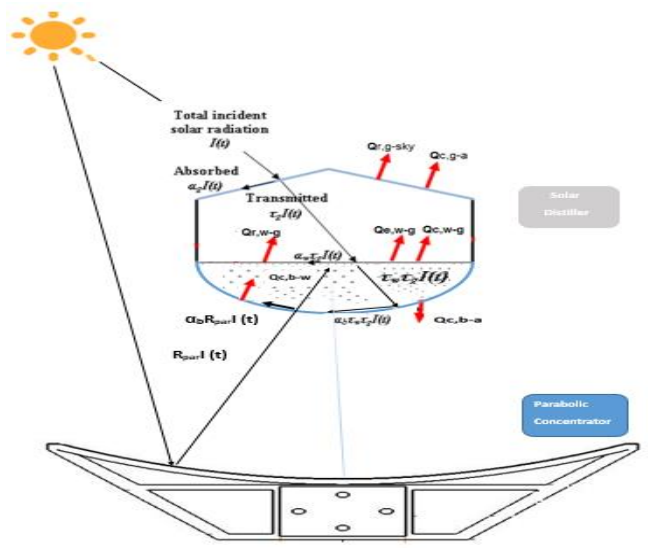

Fig. 2. Heat transfer process in new design of device

\subsection{The energy balance for the glass cover}

The energy balance equations of the glass cover are the following:

$$
\begin{gathered}
C_{p g} M_{g} \frac{d T_{g}}{d t}=Q_{\text {in }}-Q_{\text {out }} \\
Q_{\text {in }}=\alpha_{g} A_{g} I_{(t)}+Q_{c, W-g}+Q_{e, W-g}+Q_{r, W-g} \\
Q_{\text {out }}=Q_{c, g-a}+Q_{r, g-s k y}
\end{gathered}
$$

Where $Q_{\text {in }}$ is the energy entering and gained by the glass.

Where $Q_{\text {out }}$ is the energy that the glass losses.

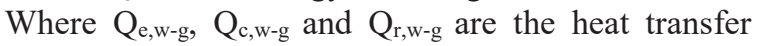
fluxes from the brackish water and the glass cover through evaporation, convection and radiation, respectively.

$\mathrm{Q}_{\mathrm{c}, \mathrm{g}-\mathrm{a}}$ represents the heat transfer flux from the glass cover and the ambient air through convection.

$\mathrm{Q}_{\mathrm{r}, \mathrm{g} \text {-sky }}$ represents the heat transfer flux from the glass cover to the sky through radiation.

$\alpha_{\mathrm{g}} \mathrm{A}_{\mathrm{g}} \mathrm{I}_{(\mathrm{t})}$ is portion of the solar incident radiation is absorbed by the glass cover.

The heat transfer flux between the brackish water and the glass cover caused by the convection is calculated as follows:

$$
Q_{c, w-g}=h_{c, w-g} A_{w}\left(T_{w}-T_{g}\right)
$$


Where $h_{c, w-g}$ is the heat transfer coefficient by convection. It is given by [9, 16-19]

$$
h_{c, w-g}=0.884 \times\left[\left(T_{w}-T_{g}\right)+\frac{\left(P_{w}-P_{g}\right)\left(T_{w}+273\right)}{\left(268.9 \times 10^{3}-P_{w j}\right)}\right]^{1 / 3}
$$

Where $\mathrm{P}_{\mathrm{g}}$ and $\mathrm{P}_{\mathrm{w}}$ indicate the pressures of saturated water vapor at the temperatures of the glass cover and water respectively, which are given as follows:

$$
\begin{aligned}
& P_{w}=\exp \left(25.317-\frac{5144}{T_{w}+273.15}\right) \\
& P_{g}=\exp \left(25.317-\frac{5144}{T_{g}+273.15}\right)
\end{aligned}
$$

The heat transfer flux between the brackish water and the glass cover caused by the evaporation is calculated as follows:

$$
Q_{e, w-g}=h_{e, w-g} A_{w}\left(T_{w}-T_{g}\right)
$$

Where $h_{e, w-g}$ is the heat transfer coefficient caused by the evaporation. It is given by [9, 16-19] and using the following expression:

$$
h_{e, w-g}=0.016273 \times h_{c, W-g} \times \frac{\left(P_{w}-P_{g}\right)}{\left(T_{w}-T_{g}\right)}
$$

The radiative heat transfer flux between the glass cover and water is calculated by the following expression:

$$
Q_{r, w-g}=h_{r, w-g} A_{w}\left(T_{w}-T_{g}\right)
$$

Where $h_{r, w-g}$ is the radiative heat transfer coefficient of water to glass cover using Stefan - Boltzmann law and from [20].

$$
\begin{aligned}
& h_{r, w-g}=\varepsilon_{e f f} \sigma\left[\left(T_{w}+273\right)^{4}-\left(T_{g}+273\right)^{4}\right] /\left(T_{w}-\right. \\
& \left.T_{g}\right)
\end{aligned}
$$

Where $\sigma$ is the constant of Stefan Boltzmann $\sigma=5.67 \times 10^{-8}\left(\mathrm{w} / \mathrm{m}^{2} . \mathrm{k}\right)$.

Where $\varepsilon_{\text {eff }}$ is the effective diffusivity given by:

$$
\varepsilon_{\text {eff }}=\frac{1}{\frac{1}{\varepsilon_{W}}+\frac{1}{\varepsilon_{g}}-1}
$$

Where $\varepsilon_{\mathrm{w}}=0.96$ and $\varepsilon_{\mathrm{g}}=0.88$ are the water and the glass emissivity, respectively.

After, replacing formulas (7) in (6), (11) in (10) and (14) and (13) in (12) and substituting in equation (4), the equation becomes as follows:

$$
\begin{aligned}
& Q_{i n}=\alpha_{g} A_{g} I_{(t)}+0.884 \times\left[\left(T_{w}-T_{g}\right)+\right. \\
& \left.\frac{\left(P_{w}-P_{g}\right)\left(T_{w}+273\right)}{\left(268.9 \times 10^{3}-P_{w}\right)}\right]^{\frac{1}{3}} A_{w}\left(T_{w}-T_{g}\right)+0.01439 \times\left[\left(T_{w}-\right.\right. \\
& \left.\left.T_{g}\right)+\frac{\left(P_{w}-P_{g}\right)\left(T_{w}+273\right)}{\left(268.9 \times 10^{3}-P_{w}\right)}\right]^{\frac{1}{3}} A_{w}\left(P_{w}-P_{g}\right)+ \\
& \frac{\sigma A_{w}\left[\left(T_{w}+273\right)^{4}-\left(T_{g}+273\right)^{4}\right]}{\frac{1}{\varepsilon_{w}}+\frac{1}{\varepsilon_{g}}-1}
\end{aligned}
$$

The convective heat transfer between the glass cover and the ambient air.

$$
Q_{c_{r},-a}=h_{c, g-a} A_{g}\left(T_{g}-T_{a}\right)
$$

Where $\mathrm{h}_{\mathrm{c}, \mathrm{g}-\mathrm{a}}$ is the convection heat transfer coefficient can be determined by the suggested equation by Johnson et al. [21]:

$h_{c, g-a}=\left\{\begin{array}{c}2.8+3 V_{w d}, \text { if } V_{w d} \leq 5 \mathrm{~m} / \mathrm{sec} \\ 2.8+3.8 V_{w d}, \text { if } V_{w d}>5 \mathrm{~m} / \mathrm{sec}\end{array}\right.$

Where $\mathrm{V}_{\mathrm{wd}}$ is the wind speed average in meter per second.

The radiative heat losses from the glass cover and the ambient air can be expressed as follows:

$$
Q_{r, g_{s k y}}=h_{r, g-s k y} A_{g}\left(T_{g}-T_{s k y}\right)
$$

The radiation heat transfer coefficient $\left(\mathrm{h}_{\mathrm{r}, \mathrm{g} \text {-sky }}\right)$ is given by:

$$
\begin{aligned}
& h_{r, g-s k y}=\varepsilon_{g} \sigma\left[\left(T_{g}+273\right)^{4}-\left(T_{s k y}+273\right)^{4}\right] /\left(T_{g}-\right. \\
& \left.T_{s k y}\right)
\end{aligned}
$$

Where the temperature of sky $\left(\mathrm{T}_{\text {sky }}\right)$ given by [20-22]

$$
T_{s k y}=0.055 T_{a}^{1.5}
$$

After, replacing formulas (17) in (16) and (19) in (18) and by substituting in equation (5), the equation becomes as follows:

$$
\begin{aligned}
& Q_{\text {out }}=h_{c, g-a} A_{g}\left(T_{g}-T_{a}\right)+\varepsilon_{g} \sigma A_{g}\left[\left(T_{g}+273\right)^{4}-\right. \\
& \left.\left(T_{s k y}+273\right)^{4}\right]
\end{aligned}
$$

The heat transfer equation at the glass cover is more complicated. The glass cover temperature depends on a large number of variables and different parameters. A simplified expression, using (15) and (21) by substituting in equation ( 3 ), could be obtained as follows: 


$$
\begin{aligned}
& C_{p g} M_{g} \frac{d T_{g}}{d t}=\alpha_{g} A_{g} I_{(t)}+0.884 \times\left[\left(T_{w}-T_{g}\right)+\right. \\
& \left.\frac{\left(P_{w}-P_{g}\right)\left(T_{w}+273\right)}{\left(268.9 \times 10^{3}-P_{w}\right)}\right]^{\frac{1}{3}} A_{w}\left(T_{w}-T_{g}\right)+0.01439\left[\left(T_{w}-T_{g}\right)+\right. \\
& \left.\frac{\left(P_{w}-P_{g}\right)\left(T_{w}+273\right)}{\left(268.9 \times 10^{3}-P_{w}\right)}\right]^{\frac{1}{3}} A_{w}\left(P_{w}-P_{g}\right)+ \\
& \frac{\sigma A_{w}\left[\left(T_{w w}+273\right)^{4}-\left(T_{g}+273\right)^{4}\right]}{\frac{1}{\varepsilon_{w}}+\frac{1}{\varepsilon_{g}}}-h_{c, g-a} A_{g}\left(T_{g}-T_{a}\right)- \\
& \varepsilon_{g} \sigma A_{g}\left[\left(T_{g}+273\right)^{4}-\left(T_{s k y}+273\right)^{4}\right]
\end{aligned}
$$

Dividing equation (22) by the quantity $\left(\mathrm{C}_{\mathrm{pg}} \mathrm{M}_{\mathrm{g}}\right)$ leads to the differential equation in the following form:

$$
\begin{aligned}
& \frac{d T_{g}}{d t}=\frac{a_{g} A_{g} I_{(t)}}{c_{p g} M_{g}}+\frac{0.884}{c_{p g} M_{g}} \times\left[\left(T_{w}-T_{g}\right)+\right. \\
& \left.\frac{\left(P_{w}-P_{g}\right)\left(T_{w}+273\right)}{\left(268.9 \times 10^{3}-P_{w}\right)}\right]^{\frac{1}{3}} A_{w}\left(T_{w}-T_{g}\right)+\frac{0.01439}{c_{p g} M_{g}} \times\left[\left(T_{w}-T_{g}\right)+\right. \\
& \left.\frac{\left(P_{w}-P_{g}\right)\left(T_{w}+273\right)}{\left(268.9 \times 10^{3}-P_{w}\right)}\right]^{\frac{1}{3}} A_{w}\left(P_{w}-P_{g}\right)+ \\
& \frac{\sigma A_{w}\left[\left(T_{w}+273\right)^{4}-\left(T_{g}+273\right)^{4}\right]}{c_{p g} M_{g}\left(\frac{1}{\varepsilon_{w}}+\frac{1}{\varepsilon_{g}}-1\right)}-\frac{h_{c, g-a^{A}} A_{g}}{c_{p g} M_{g}}\left(T_{g}-T_{a}\right)- \\
& \frac{\varepsilon_{g} \sigma A_{g}}{c_{p g} M_{g}}\left[\left(T_{g}+273\right)^{4}-\left(T_{s k y}+273\right)^{4}\right]
\end{aligned}
$$

\subsection{The energy balance for the brackish water}

The energy balance equations of the brackish water are the following:

$$
\begin{aligned}
& C_{p w} M_{w} \frac{d T_{w}}{d t}=Q_{\text {in }}-Q_{\text {out }} \\
& Q_{\text {in }}=\alpha_{w} \tau_{g} A_{w} I_{(t)}+Q_{c, b-w} \\
& Q_{\text {out }}=Q_{c, w-g}+Q_{\theta_{,},-g}+Q_{r, w-g}
\end{aligned}
$$

$\alpha_{\mathrm{w}} \tau_{\mathrm{g}} \mathrm{A}_{\mathrm{w}} \mathrm{I}_{(\mathrm{t})}$ is fraction of the solar incident radiation is absorbed by the brackish water.

Where $\mathrm{Q}_{c, b-w}$ is the energy loss through convection, from the half-cylinder basin and the brackish water.

$$
Q_{c, b-w}=h_{c, b-w} A_{b}\left(T_{b}-T_{w}\right)
$$

Where $h_{c, b-w}$ is the convection heat transfer coefficient that can be determined using the correlation of Nusslet Number for horizontal cylinder [23]:

$$
h_{c_{s} b-w}=N u \times \frac{K_{W}}{L_{c}}
$$

Where Gr, Pr and Nu are the Grashof, Prandtl and Nusselt numbers given by:

$$
\begin{gathered}
N u=a(G r \times P r)^{n} \\
G r=\frac{\beta g L_{c}^{3} \rho^{2} \Delta T}{\mu^{2}}, \Delta T=T_{b}-T_{w}, \beta=\frac{1}{\left(T_{i}+273\right)}, \\
T_{i}=\frac{T_{b}+T_{W}}{2} \\
\operatorname{Pr}=\frac{\mu c_{p}}{K}
\end{gathered}
$$

The values of the constants for the Nusslet number equation can be estimated from the Table 1 .

Where $\mathrm{K}_{\mathrm{w}}$ and $\mathrm{L}_{\mathrm{c}}$ are the water heat conductivity and the characteristic length of the absorber.

Table 1. Estimation of constants a and $\mathrm{n}$ for the Nusslet number equation [23]

\begin{tabular}{|c|c|c|c|}
\hline Surface & (Gr.Pr) & a & n \\
\hline Vertical & $10^{4}-10^{9}$ & 0.59 & 0.25 \\
plates/cylinders & $10^{9}-10^{12}$ & 0.13 & 0.33 \\
\hline Horizontal pipes & $10^{3}-10^{9}$ & 0.53 & 0.25 \\
\hline Horizontal plates & $10^{5}-2 \times 10^{7}$ & 0.54 & 0.25 \\
\hline $\begin{array}{c}\text { Heated face up } \\
\text { or cool face down }\end{array}$ & $2 \times 10^{7}-$ & 0.14 & 0.33 \\
\hline $\begin{array}{c}\text { Vertical plates, } \\
\text { heated face up or } \\
\text { cooled face down }\end{array}$ & $3 \times 10^{10}-$ & 0.27 & 0.25 \\
\hline
\end{tabular}

After, replacing formula (28) in (27) and by substituting in equation (25), the equation becomes as follows:

$Q_{i n}=\alpha_{w} \tau_{g} A_{w} I_{(t)}+\frac{N u K_{w}}{L_{c}} A_{b}\left(T_{b}-T_{w}\right)$

Replacing formulas (7) in (6), (11) in (10) and (14) and (13) in (12) and by substituting in equation (26) gives the expression of the heat losses as follows:

$Q_{\text {out }}=0.884 \times\left[\left(T_{w}-T_{g}\right)+\right.$ $\left.\frac{\left(P_{w}-P_{g}\right)\left(T_{w}+273\right)}{\left(268.9 \times 10^{3}-P_{w}\right)}\right]^{\frac{1}{3}} A_{w}\left(T_{w}-T_{g}\right)+0.01439 \times\left[\left(T_{w}-\right.\right.$ $\left.\left.T_{g}\right)+\frac{\left(P_{W}-P_{g}\right)\left(T_{w}+273\right)}{\left(268.9 \times 10^{3}-P_{w}\right)}\right]^{\frac{1}{3}} A_{w}\left(P_{w}-P_{g}\right)+$ $\frac{\sigma A_{W}\left[\left(T_{W}+273\right)^{4}-\left(T_{g}+263\right)^{4}\right]}{\frac{1}{\varepsilon_{W}}+\frac{1}{\varepsilon_{g}} 1}$

Equations (32) and (33) are gathered in equation (24) to obtain the energy balance in the brackish water: 


$$
\begin{aligned}
& C_{p g} M_{w} \frac{d T_{w}}{d t}=\alpha_{w} \tau_{g} A_{w} I_{(t)}+\frac{N u \times K_{w}}{L_{c}} A_{b}\left(T_{b}-T_{w}\right)- \\
& 0.884 \times\left[\left(T_{w}-T_{g}\right)+\frac{\left(P_{w}-p_{g}\right)\left(T_{w}+273\right)}{\left(268.9 \times 10^{3}-P_{w}\right)}\right]^{\frac{1}{3}} A_{w}\left(T_{w}-T_{g}\right)- \\
& 0.01439 \times\left[\left(T_{w}-T_{g}\right)+\frac{\left(P_{w}-P_{g}\right)\left(T_{w}+273\right)}{\left(268.9 \times 10^{3}-P_{w}\right)}\right]^{\frac{1}{3}} A_{w}\left(P_{w}-\right. \\
& \left.P_{g}\right)-\frac{\sigma A_{w}\left[\left(T_{w}+273\right)^{4}-\left(T_{g}+273\right)^{4}\right]}{\frac{1}{\varepsilon_{w}}+\frac{1}{\varepsilon_{g}}-1}
\end{aligned}
$$

After dividing equation (34) by the quantity $\left(\mathrm{C}_{\mathrm{pw}} \mathrm{M}_{\mathrm{w}}\right)$ a second ordinary differential equation (ODE) is obtained and has the following form

$$
\begin{aligned}
& \frac{d T_{w}}{d t}=\frac{a_{w} \tau_{g} A_{w} I_{(t)}}{C_{p g} M_{g}}+\frac{N u \times K_{w}}{C_{p w} M_{w} L_{c}} A_{b}\left(T_{b}-T_{w}\right)- \\
& \frac{0.884}{C_{p w} M_{w}}\left[\left(T_{w}-T_{g}\right)+\frac{\left(P_{w}-P_{g}\right)\left(T_{w}+273\right)}{\left(268.9 \times 10^{3}-P_{w}\right)}\right]^{\frac{1}{3}} A_{w}\left(T_{w}-T_{g}\right)- \\
& \frac{0.01439}{C_{p w} M_{W}}\left[\left(T_{w}-T_{g}\right)+\frac{\left(P_{w}-P_{g}\right)\left(T_{w}+273\right)}{\left(268.9 \times 10^{3}-P_{w}\right)}\right]^{\frac{1}{3}} A_{w}\left(P_{w}-P_{g}\right)- \\
& \frac{\sigma A_{w}\left[\left(T_{w}+273\right)^{4}-\left(T_{g}+273\right)^{4}\right]}{C_{p w} M_{w}\left(\frac{1}{E_{W}}+\frac{1}{\varepsilon_{g}}-1\right)}
\end{aligned}
$$

\subsection{The energy balance for the half-cylinder basin}

The energy balance equations of the half-cylinder basin are the following:

$$
\begin{gathered}
C_{p b} M_{b} \frac{d T_{b}}{d t}=Q_{\text {in }}-Q_{\text {out }} \\
Q_{\text {in }}=\alpha_{b} \tau_{g} \tau_{w} A_{b} I_{(t)}+\alpha_{b} R_{p} A_{a p e r} I_{(t)} \\
Q_{\text {out }}=Q_{c, b-w}+Q_{c, b-a}
\end{gathered}
$$

Where $\alpha_{\mathrm{b}} \tau_{\mathrm{w}} \tau_{\mathrm{g}} \mathrm{A}_{\mathrm{b}} \mathrm{I}_{(\mathrm{t})}$ is solar radiation is absorbed by the half-cylinder basin.

$\alpha_{b} R_{p} A_{a p e r} I_{(t)}$ represents the solar energy reflected from the parabolic concentrator and absorbed by the half-cylinder basin.

$\mathrm{Q}_{\mathrm{c}, \mathrm{b}-\mathrm{a}}$ denotes the heat transfer flux through convection, from the half-cylinder basin and the ambient air.

$$
Q_{c_{r} b-a}=h_{c, b-a} A_{b}\left(T_{b}-T_{a}\right)
$$

Where $h_{c, b-a}$ is the convection heat transfer coefficient that is determined as shown in equation (17).

After, replacing formulas (17) in (39), (28) in (27) and substituting in equation (38), the equation becomes as follows:

$$
Q_{\text {out }}=\frac{N u \times K_{w}}{L_{c}} A_{b}\left(T_{b}-T_{w}\right)+h_{c_{s} b-a} A_{b}\left(T_{b}-T_{a}\right)
$$

By substituting equations (37) and (40) in equation (36), then gathered in one equation (41).

$$
\begin{aligned}
& C_{p b} M_{b} \frac{d T_{b}}{d t}=\alpha_{b} \tau_{w} \tau_{g} A_{b} I_{(t)}+\alpha_{b} R_{p} A_{a p e r} I_{(t)}- \\
& \frac{N u \times K_{w}}{L_{n}} A_{b}\left(T_{b}-T_{w}\right)-h_{c, b-a} A_{b}\left(T_{b}-T_{a}\right)
\end{aligned}
$$

After the division of equation (41) by the quantity $\left(\mathrm{C}_{\mathrm{pb}} \mathrm{M}_{\mathrm{b}}\right)$ we obtain the third differential equation which can be rewritten in the following form:

$$
\begin{aligned}
& \frac{d T_{b}}{d t}=\frac{a_{b} \tau_{w} \tau_{g} A_{b} I_{(t)}}{c_{p b} M_{b}}+\frac{a_{b} R_{p} A_{a p e r} I_{(t)}}{c_{p b} M_{b}}-\frac{N u \times K_{w}}{L_{c} C_{p b} M_{b}} A_{b}\left(T_{b}-\right. \\
& \left.T_{W}\right)-\frac{h_{c, b-a}}{c_{p b} M_{b}} A_{b}\left(T_{b}-T_{a}\right)
\end{aligned}
$$

\section{Hourly Productivity}

The water vapor mass flow rate per unit time transferred the free brackish water surface to the moist air by heat transfer between the water and glass cover surfaces caused by the evaporation is determined, as suggested by Sarray et al. [2]:

$$
\dot{M}_{e V}=\frac{3600 \times Q_{e, W-g}}{h_{f g}}
$$

Where $h_{f g}$ is the water evaporation's latent heat given by Aghaei Zoori et al. [24]:

$$
h_{f g}=\left\{\begin{array}{c}
3.1615 \times\left[10^{6}-\left(761.6 \times T_{f}\right)\right], \\
\text { if } T_{f} \geq 70 \mathrm{~m} / \mathrm{sec} \\
{\left[\begin{array}{c}
10^{6}-\left\{947.79 \times T_{f}\right)+ \\
\left(0.013132 \times T_{f}^{2}\right)- \\
\left(0.0047974 \times T_{f}^{3}\right)
\end{array}\right],} \\
\text { if } T_{f}<70 \mathrm{~m} / \mathrm{sec}
\end{array}\right.
$$

Where the temperature of the air-water mixture $T_{f}$ is calculated to be the mathematical mean value of the glass cover and water temperatures:

$$
T_{f}=\frac{T_{g}+T_{w}}{2}
$$

\section{Energy efficiency}

The solar distiller's overall thermal efficiency is the ratio of evaporative heat transfer to solar radiation on the halfcylinder absorber that can be written in following form [24]:

$$
\eta_{t h}=\frac{\sum M_{e v} h_{f g}}{3600 A_{b} \sum I_{(t)}}
$$

Where $\mathrm{M}_{\mathrm{ev}}$ the produced water amount as given by equation (43). 


\section{Numerical resolution}

The system of the three ODE equation (23), (35) and (42) is solved using a simulation code based on the 4th order Runge-Kutta method under MATLAB ${ }^{\circledR}$ to find $\mathrm{T}_{\mathrm{g}}$, $\mathrm{T}_{\mathrm{w}}$ and $\mathrm{T}_{\mathrm{b}}$. Through the MATLAB code, the productivity of water and the system efficiency were determined by using equations (43), (46). The design and physical operating parameters used in theoretical model are illustrated in Table 2.

Table 2. Physical properties used in theoretical calculation

\begin{tabular}{|c|c|c|c|}
\hline & $\begin{array}{c}\text { Density } \\
\boldsymbol{\rho}\left(\mathbf{k g} / \mathbf{m}^{\mathbf{3}}\right)\end{array}$ & $\begin{array}{c}\text { Specific Heat } \\
\mathbf{C p}(\mathbf{J} / \mathbf{k g} . \mathbf{k})\end{array}$ & $\begin{array}{c}\text { Thermal } \\
\text { Conductivity } \\
\mathbf{K}(\mathbf{W} / \mathbf{m} . \mathbf{k})\end{array}$ \\
\hline Glass & 2530 & 800 & 1.02 \\
\hline $\begin{array}{c}\text { Brackish } \\
\text { water }\end{array}$ & 1022.61 & 4180 & 0.67 \\
\hline absorber & 2700 & 896 & 204 \\
\hline
\end{tabular}

\section{The daily rate of solar radiation, wind speed and ambient temperature for Rabat region - Morocco}

It is first necessary to define the heat without solar irradiation conditions. In our case, Morocco's RabatSale-Kenitra that has a high interesting geographical position is considered.

The solar radiation data were obtained from measurements of the European satellite PVGIS [25-27] with metrological parameters on the zone of the location $34^{\circ} 01^{\prime} 53.34^{\prime \prime}$ North, 650'39.72" West, and elevation is $139 \mathrm{~m}$. The optimal inclination angle is 31 degrees [11].

It is observed from Figure 3 that the incident solar radiation rises continuously from 7:22 in the morning and reaches a maximum amount of $860 \mathrm{~W} / \mathrm{m}^{2}$ at 12.22 and after that it starts to decrement with time until 17.52.

Additionally, the variations of ambient temperature and the wind speed with time are taken into account.

The maximal wind speed of $4.85 \mathrm{~m} / \mathrm{s}$ is recorded at 15.22 to 15.52 and the maximal ambient temperature of $33{ }^{\circ} \mathrm{C}$ is recorded at 12.22 .



Fig. 3. Estimated by PVGIS of the daily solar radiation, wind speed and ambient temperature for region of Rabat in Morocco.

\section{Results and discussion}

The theoretical study of new design of a concentration based solar distiller was carried out to evaluate the performance and the developed design.

As for the figures shown below, all the parameters in the graphs show the same tendency. They gradually increase from morning and reache the maximum values at $\mathrm{t}=$ 12:22 and then decrease until sunset.

\subsection{The glass cover, brackish water and half- cylinder basin temperatures}

Figure 4 illustrates the evolution of the glass cover, brackish water and half-cylinder basin temperatures for the solar concentration distiller. All the parameters show the same tendency, they begin to increase until the achievement of peaks assessed at 12.22. The maximum value of the glass cover, brackish water and half-cylinder basin temperatures is $83.77{ }^{\circ} \mathrm{C}, 93.09{ }^{\circ} \mathrm{C}$ and $107.4{ }^{\circ} \mathrm{C}$, respectively. After this instant, they start to fell down until the sunset.

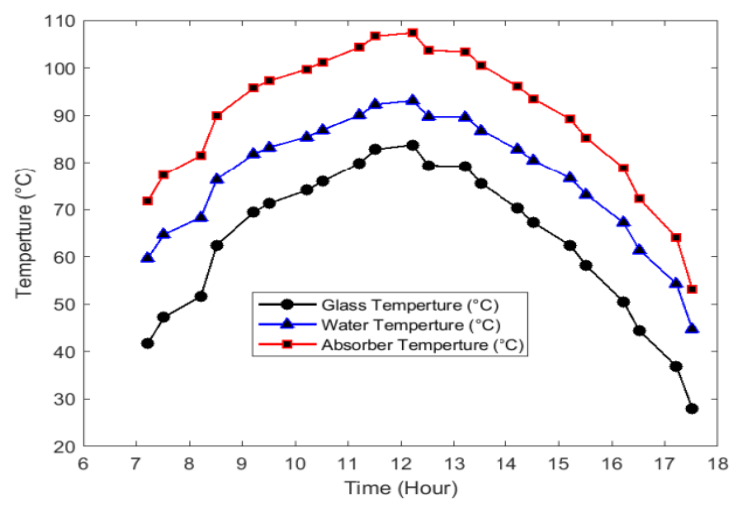

Fig. 4. The theoretical variation of the glass, brackish water and absorber temperatures

\subsection{Hourly Productivity}

Figure 5 shows the productivity of distilled water, the largest amount was harvested between 11:22 to 14:22 where the solar radiation is maximum.

The maximum value of the productivity is $1.45 \mathrm{~kg} / \mathrm{m}^{2} . \mathrm{hr}$.

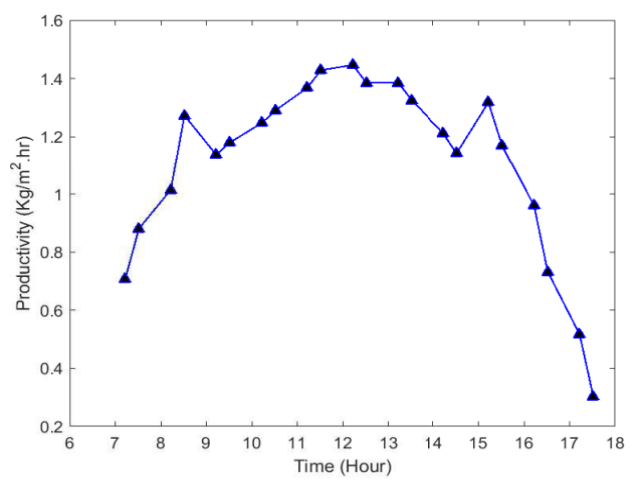

Fig. 5. Variation of the water productivity 


\subsection{The solar concentration distiller efficiency}

Figure 6 shows the solar concentration distiller efficiency, where the efficiency increases with the increase of solar energy and the amount of distilled water, it has the greatest value at 12.22 by $93 \%$.

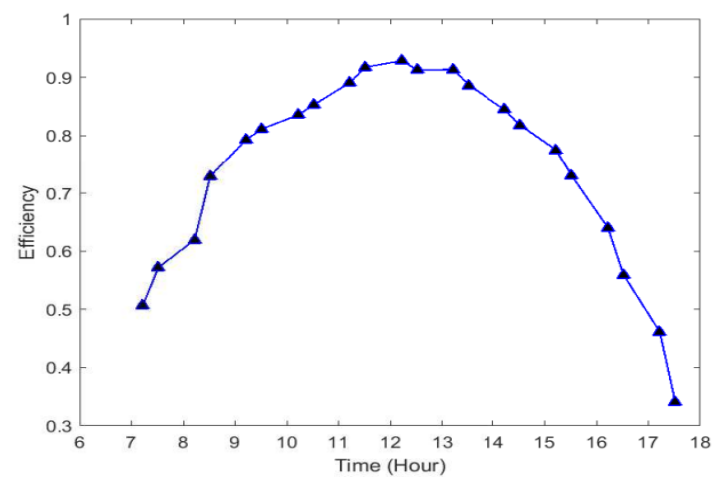

Fig. 6. The solar concentration distiller efficiency

\section{Conclusions}

The present paper proposes the study of a solar desalination device that consists of a concentrated solar system by parabolic trough concentrator and a halfcylinder basin.

The goal of the new design of this system is to obtain high throughput of distilled water.

In this work, we focused on the theoretical heat transfer study on the solar distiller.

The study was based on the energy balance of the components (the glass cover-the brackish water-the absorber).

A group of differential equations is used to determine different elements temperatures. The system of the obtained energy balance equations was solved using a computer simulation code based on the 4th order Runge-Kutta method with programming under MATLAB® .This study was carried out according with the meteorology of the region of the (Rabat-sale-kenitra) of Morocco for test.

The obtained results show that the solar distiller performance and efficiency with the solar concentrator is better than the solar distiller without the solar concentrator. As well, these results encourage the development and improvement our research to increase the heat rate based on the solar collection system.

This research through good results is very useful for desalination by obtaining pure distilled water suitable for drinking. And that the device that will be manufactured can be used in areas that suffer from a shortage of drinking water. And also the use of a desalination system via solar concentrators does not affect the environment because the energy source for it is the sun and it does not emit any pollution, noise, etc.

All these conclusions encourage us to develop and improve our research in desalination of non-drinking water via solar energy.

\section{References}

1. K. V. Kumar, R. K. Bai, Performance study on solar still with enhanced condensation, Desalination., 230, 51-61, (2008)

2. Y. Sarray, N. Hidouri, A. Mchirgui, A. B. Brahim, Study of heat and mass transfer phenomena and entropy rate of humid air inside a passive solar still, Desalination, 409, 80-95, (2017)

3. M. A. Shannon, P. W. Bohn, M. Elimelech, J. G. Georgiadis, B. J. Mariñas, A. M. Mayes, Science and technology for water purification in the coming decades, Nature, 452, 301-310, (2008)

4. B. Chaouchi, A. Zrelli, S. Gabsi, Desalination of brackish water by means of a parabolic solar concentrator, Desalination, 217, 118-126, (2007)

5. A.-J. N. Khalifa, A. S. Al-Jubouri, M. K. Abed, An experimental study on modified simple solar stills, Energy Convers. Manage., 40, 1835-1847, (1999)

6. N. E. Gharbi, H. Derbal, S. Bouaichaoui, N. Said, $A$ comparative study between parabolic trough collector and linear Fresnel reflector technologies, Energy Procedia, 6, 565-572, (2011)

7. A. B. Auti, Domestic Solar Water Desalination System, Energy Procedia, 14, 1774-1779, (2012)

8. T. Arunkumara, R. Velraja, A. Ahsanc, A.J.N. Khalifad, S. Shamse, D. Denkenbergerf, R. Sathyamurthy, Effect of parabolic solar energy collectors for water distillation, Desalin. Water Treat., 57, 21234-21242, (2016)

9. M. Bouzaid, O. Ansari, M. Taha-Janan, M. Oubrek, Experimental and Theoretical Analysis of a Novel Cascade Solar Desalination Still, FDMP, 14, 177200, (2018)

10. M. Al-harahsheh, M. Abu-Arabi, H. Mousa, Z. Alzghoul, Solar desalination using solar still enhanced by external solar collector and PCM, Appl. Therm. Eng., 128, 1030-1040, (2018)

11. S. E. Lachhab, A. Bliya, E. Al Ibrahmi, L. Dlimi, Theoretical analysis and mathematical modeling of a solar cogeneration system in Morocco, AIMS Energy, 7, 743-759, (2019)

12. M. Ghodbane, B. Boumeddane, S. Largot, Simulation Numérique d'un Concentrateur Cylindro-Parabolique en El Oued, Algérie, IJRER, 3, 68-74, (2015)

13. A. F. García, E. Zarza, L. Valenzuela, M. Pérez, Parabolic-trough solar collectors and their applications, Renewable Sustainable Energy Rev., 14, 1695-1721, (2010)

14. A. Hepbasli, Z. Alsuhaibani, A key review on present status and future directions of solar energy studies and applications in Saudi Arabia, Renewable Sustainable Energy Rev., 15, 50215050, (2011)

15. M. Ghodbane, B. Boumeddane, A numerical analysis of the energy behavior of a parabolic 
trough concentrator, J. Fundam and Appl Sci., 8, 671, (2018)

16. R. V. Dunkle, CSIRO (Australia), Solar water distillation: the roof type still and a multiple effect diffusion still. Melbourne: C.S.I.R.O., (1961)

17. G. N. Tiwari, S. A. Lawrence, S. P. Gupta, Analytical study of multi-effect solar still, Energy Convers. Manage., 29, 259-263, (1989)

18. S. Kumar, G. N. Tiwari, Estimation of convective mass transfer in solar distillation systems, Sol. Energy, 57, 459-464, (1996)

19. S. Aggarwal, G. N. Tiwari, Convective mass transfer in a double-condensing chamber and a conventional solar still, Desalination, 115, 181-188, (1998)

20. D. K. Dutt, A. Kumar, J. D. Anand, G. N. Tiwari, Performance of a double-basin solar still in the presence of dye, Appl. Energy, 32, 207-223, (1989)

21. A. Johnson, L. Mu, Y. H. Park, D. J. Valles, H. Wang, P. Xu, K. Kota, S. Kuravi, A Thermal Model for Predicting the Performance of a Solar Still with Fresnel Lens, Water, 11, 1860, (2019)

22. J. A. Duffie, W. A. Beckman, Solar engineering of thermal processes / John A. Duffie, William A. Beckman, 4th ed. Hoboken: John Wiley, (2013)

23. A. Z. Hafez, A. Soliman, K. A. El-Metwally, I. M. Ismail, Solar parabolic dish Stirling engine system design, simulation, and thermal analysis, Energy Convers. Manage., 126, 60-75, (2016)

24. H. Aghaei Zoori, F. Farshchi Tabrizi, F. Sarhaddi, F. Heshmatnezhad, Comparison between energy and exergy efficiencies in a weir type cascade solar still, Desalination, 325, 113-121, (2013)

25. M. Š́ri, T. A. Huld, E. D. Dunlop, M. Albuisson, L. Wald, Online Data and Tools for Estimation of Solar Electricity in A frica:the PVGIS Approach, Proceedings from 21st European Photovoltaic Solar Energy Conference and Exhibition, 4-8 October 2006, Dresden, Germany (2006)

26. P. G. Kale, R. Tarai, Development of Rasterized Map using PVGIS for Assessment of Solar PV Energy Potential of Odisha, IJRER, 6, 61-73, (2016)

27. R. P. Kenny, T. A. Huld, S. Iglesias, Energy Rating of PV Modules based on PVGIS Irradiation and Temperature Database, 21st European Photovoltaic Solar Energy Conference, 4-8 September 2006, Dresden, Germany (2006) 